\title{
The promises and pitfalls of codification of governance in sport as legitimacy work
}

\author{
Richard Tacon and Geoff Walters
}

\section{Introduction}

Over the last 20 years, there has been a process of 'codification' across the nonprofit sport sector in many countries, wherein governments, national sport agencies, or other bodies have introduced codes of good governance (Walters \& Tacon 2018). This is an extension of the broader process of codification that began in the corporate sector in the 1990s, following a series of high-profile corporate governance failures, and spread to the public sector and non-profit sector in many countries (Nordberg \& McNulty 2013). In sport, more than 30 governance codes, or lists of good governance principles, have been published (Chappelet 2018), ranging from early examples of national-level principles (e.g. Australian Sports Commission 2005; UK Sport 2004) to more recent sets of international principles, e.g. the five principles (with ten indicators for each principle) agreed by the Association of Summer Olympic International Federations (ASOIF 2016).

In the UK, which provides the main context for this chapter, there have been four codes. The first was developed by UK Sport, in collaboration with the Institute of Chartered Secretaries and Administrators (UK Sport 2004). The second was developed by the Sport and Recreation Alliance in 2011 (and then re-issued in 2014) (Sport and Recreation Alliance 2011, 2014). The third, labelled a 'governance strategy', was issued by Sport England in 2012 (Sport England 2012), and the fourth, the Code for Sports Governance, was jointly issued by Sport England and UK Sport in December 2016 (Sport England/UK Sport 2016). This latter code is mandatory for organisations receiving public funding and, in that sense, is different to the voluntary codes and sets of good governance principles that are published elsewhere.

Research on 'codification' in the corporate sector has mostly been at a macro-level, looking at whether companies have formally adopted codes of governance and what effects (if any) this has had on organisational performance (Aguilera \& Cuervo-Cazurra 2004; Seidl et al. 2013). There has been much less research at organisational level, looking at why companies have decided to adopt codes, or how (if at all) they have implemented their principles. This is also true in the public and non-profit sectors. In large part, this is because of the difficulty 
of gaining access to boards to open up what Leblanc and Schwartz (2007) call the 'black box' of board process.

In sport, while there has obviously been significant research on sport governance for a number of years, there was, until recently, very little research specifically on codification. This has changed in the last few years. In 2018, we published an article examining codification in the UK non-profit sport sector, looking at the role of national sport agencies and national governing bodies of sport (Walters \& Tacon 2018). Subsequently, Parent and Hoye (2018) published a systematic review of research examining the impact of governance principles on sport organisations' governance practices and performance. Then, Geeraert (2019) examined international federations' efforts at self-regulation, drawing on compliance theory, and McLeod et al. (2020) examined governance convergence in India, employing institutional theory.

Together, these studies offer valuable insight into various aspects of codification at national and international level. However, as all the authors note, there is more that needs to be examined. In this chapter, we look at what happens when national sport federations formally adopt codes of governance and we seek to 'get at' this through the theoretical lens of legitimacy and, in particular, the notion of legitimacy work. Legitimacy work has been defined as "purposeful activity to shape others' evaluation of something as desirable, proper or appropriate" (Lefsrud et al. 2020 , p. 2). The adoption of a code of governance can be framed as an organisational practice enacted by a sport organisation to gain legitimacy among particular stakeholders. We examine this critically, drawing on board members' accounts of the advantages and disadvantages - the promises and pitfalls_-of formally adopting codes as a legitimising tool.

Adopting a legitimacy perspective should be useful for practitioners. It is always important for board members to critically reflect on why they pursue the practices they do and what the implications are. For example, if boards decide to adopt a code of governance primarily to improve organisational practices, this is likely to shape the way they are understood and implemented differently than if the primary motivation is to signal things to others in the sector.

In this chapter, we first discuss the concept of legitimacy work in more detail. Then, we draw on empirical evidence from two research projects to examine, from a legitimacy perspective, why board members in national sport federations signed up to codes, what they considered they 'got' out of them and how they shaped board practices and other aspects of the organisation. Finally, we conclude by offering insight into the usefulness of legitimacy work as a concept for understanding the actions of sport organisations and the implications this approach has for researchers and practitioners.

\section{Theoretical lens: Legitimacy work}

Legitimacy, as defined by Suchman (1995, p. 574), is a "generalised perception or assumption that the actions of an entity are desirable, proper, or appropriate within some socially constructed system of norms, values, beliefs, and definitions". 
In the organisational context, legitimacy work refers to the activities that organisations engage in that support and reinforce a particular course of action that is seen by others (both externally and internally) as desirable (Lefsrud et al. 2020). It has long been understood that organisations adopt particular structures or ways of working not necessarily because they are more efficient or productive, but because they confer legitimacy among stakeholders within the institutional environment (Meyer \& Rowan 1977).

Legitimacy work, as a way of understanding organisational decision-making, can be applied broadly to organisational governance. Institutional pressures have led to the increasing homogeneity of board structures (e.g. reductions in board size and the appointment of independent board members) and board practices (e.g. the expectation that boards undergo external evaluations). Formally adopting a code of governance can be seen as one way in which an organisation seeks legitimacy, demonstrating how the organisation is moving along a reform agenda driven by the central narrative underpinning codes of governance, namely that they are considered 'best practice'. This has been recognised in the corporate sector: Aguilera and Cuervo-Cazurra (2009) and Nordberg and McNulty (2013) both explain how codification brought with it the requirement for organisations to demonstrate good governance. Likewise, Ebrahim (2010, p. 11), in his analysis of accountability in the non-profit sector, argues that the adoption of codes is a way to "send signals of good housekeeping to the outside world".

However, we can also see the role that legitimacy work plays within an organisation. Gaining external legitimacy requires individual actors within an organisation to engage in decision-making behaviour that aligns with the norms and expectations of external stakeholders. This behaviour, however, needs to be accepted within the organisation, and therefore the process of creating external legitimacy also co-exists with internal legitimising around the nature of work that individuals undertake within an organisation. This was emphasised by Drori and Honig (2013), who argued that the creation of legitimacy is both a process of external and internal forms of legitimacy. Internal legitimacy is defined as 'the acceptance or normative validation of an organisational strategy through the consensus of its participants, which acts as a tool that reinforces organisational practices and mobilises organisational members around a common ethical, strategic or ideological vision' (Drori \& Honig 2013, p. 347).

All of this implies that to understand codification from an organisational perspective, we need to understand how and why board members take decisions about codes of governance and how (if at all) they influence board practices. Getting this 'insider' perspective, however, is often difficult. This is why, as Leblanc and Schwartz (2007), among others, have argued, governance processes are still something of a 'black box'. And even if it is possible to gain access to boards, this does not mean that board members will explicitly discuss whether they adopt codes for legitimacy and/or other purposes. Nevertheless, we try to do this here, by drawing on some relevant empirical evidence. In doing so, we align with Pugliese et al. 
(2009, p. 301), who argue that we should see boards as "decision-making groups whose internal processes and external context should be better understood".

\section{Adopting codes of governance: Empirical evidence from previous research}

In order to illustrate the possibilities and complexities of adopting codes of governance, the chapter now draws on empirical evidence from two separate research projects. The first was a questionnaire survey of board members at sport federations in the UK (Birkbeck/Moore Stephens 2018). The survey was conducted between August and October 2017, with 1,000 individual board members from 170 sport organisations across the UK invited to respond. The survey asked respondents a series of closed and open questions about governance issues, including open questions about what they saw as the advantages and disadvantages of formally adopting a code of good governance. Ultimately, 102 board members from 56 organisations responded, including 85 board members across 40 sport federations. For consistency, we draw only on the responses from sport federation board members. The second research project was an extended case study of one sport federation in the UK, carried out between 2011 and 2016, in which we conducted non-participant observation at board and committee meetings, semi-structured interviews with board members and executive staff and analysis of key organisational documents, including organisational strategies, board and committee reports, meeting minutes and internal memos (see Tacon et al. 2017; Walters \& Tacon 2018, for more details).

\section{Advantages of code adoption: Survey research}

In the survey, sport federation board members highlighted a number of advantages of formally adopting a code of good governance. The most regularly cited advantage was that it would promote consistency across the sector:

Consistent, strong governance across all sports.

All sports will comply to the same code and will be professionally run.

In addition, a number of respondents suggested it would drive improvements in governance practices:

Highlighting some areas where our governance could be improved slightly.

It will drive significant improvement in organisations that had poor practice. 
These were, in a sense, predictable responses and they reflect a mainstream 'managerial' view of governance codes. Among these responses, however, were a number that discussed very openly how adopting a code constituted a form of legitimacy work:

It enables us to demonstrate to our stakeholders that we are aligned to 'good practice'.

Builds confidence in the ability of [the] organisation with funders and partners that [the] organisation is fit for purpose.

The Code assists with our own credibility both internally with all our stakeholders and externally with our partners, especially commercial partners.

The notion of external legitimacy work was strong here, with many respondents focusing on the way it allowed them to demonstrate credibility to external stakeholders. However, a significant number also discussed the subtler ways in which formally adopting a code of governance allowed federations to navigate their own internal governance struggles. Some talked about this in general, i.e. across the sector:

The Code will facilitate change in some organisations with legacy structures or complex constituencies.

For too long, some sports organisations have operated as an 'old boys' club' - the new Code brings transparency and accountability. It is long overdue.

Others talked about it specifically in relation to their own federation:

A reason to force the board to discuss governance issues that they have previously ignored or not deemed a priority.

It has been the catalyst for modernising [our] governance structure. Without the potential financial penalties for non-compliance, it is highly unlikely that some of the requirements of the Code would have been passed, particularly term limits for Council membership.

There is an important distinction here between voluntary codes of good governance, which often have symbolic, legitimising value, and the most recent Code for Sports Governance in the UK, which sport federations have to comply to, in order to receive funding. It is the mandatory nature of this code (and the threat 
of public funding being withheld for non-compliance) that enabled some sport federations to push through governance reforms that otherwise might have been opposed by existing board members, or the wider membership of the federation.

\section{Disadvantages of code adoption: Survey research}

Respondents also discussed the disadvantages of adopting a code of governance and it is arguably these responses that best illustrate the complexity of this 'reform strategy' and the nature of the legitimacy work involved. First, many respondents discussed the danger of the code cultivating a 'tick-box' approach to governance that would crowd out the kind of internal cultural change that actually leads to improvements in governance:

In my experience on a range of boards, governance is most effectively improved when change comes from within. There is a danger of conforming to a template without improving underlying culture and values.

The code feels like a measuring tool. I am concerned that organisations spend their time ticking the box rather than addressing the culture and values of the organisations which, if highlighted as critical to the organisations progress, can address the decision making required to embed the code into organisations.

Second, several respondents felt that the introduction of this particular Code for Sports Governance was partly about 'legitimacy work' on the part of the UK Government and the national sport agencies, Sport England and UK Sport, i.e. a way for them to demonstrate that they were 'doing something' about governance in sport, particularly in large federations, where there have been high profile examples of governance failures:

It is a 'one size fits all' [approach] that feels very driven by the need for change in the governance of one or two major sports and does not recognise the very varied landscape that sport organisations operate in. It is also heavily focussed on simple numbers in terms of equality on boards and rather pejorative in tone towards sport bodies. Competency seems to have been substituted by the word 'Independent'.

It is important to note this was a marginal view among respondents, but it nevertheless highlights the complexity of 'codification' and the various types 
of legitimacy work involved, both among sport federations themselves and the national sport agencies and government departments that all operate in the same 'regulatory space' (Hancher \& Moran 1989).

Finally, the strongest responses concerned the potential alienation of sport federation members that might follow from the prescriptions of the code, particularly around the election of 'independent' Chairs and board members:

For an organisation heavily dependent on unpaid volunteers within its governance and service delivery activities:

- sense that control moving away from the members/volunteers to external bodies/individuals with no background in the sport

- traditional 'bottom-up' electoral processes having to be replaced by appointments with minimal member involvement.

In some areas it runs the risk of disenfranchising the volunteer administrator base that NGBs rely on. Reinforces 'us v them'.

The general thrust is to marginalise volunteers from decision-making and to restrict the opportunities for them to advance to the highest levels in the organisation. As a membership organisation, there is a mismatch with a PLC [Public Limited Company] governance structure which fits poorly, potentially exacerbating difficulty for many National Governing Bodies of Sport (NGBs) of communication between the members and the organisation, with the result that there could be an increasing alienation between the central organisation of staff and Board from the membership.

This is a really important issue, both of substance and perception. Formally complying with the Code for Sports Governance means that sport federations have to abide by particular governance prescriptions - term limits on board members, recruitment of independent board members, and so on. And while there is evidence, including the comments above, that formally adopting this code demonstrates credibility to external stakeholders, including funding bodies and commercial sponsors, the argument here from a number of board members is that, in doing so, this may well de-legitimise some federations in the eyes of their members. This raises a key question about the legitimacy work involved in adopting codes of good governance: legitimacy to whom? We discuss this below.

\section{Case study insights}

The case study research provided further, in-depth insight into code adoption and implementation in the context of one sport federation in the UK. In late 2011, the board of the federation formally signed up to the Voluntary Code of Good Governance for the Sport and Recreation Sector (Sport and Recreation 
Alliance 2011). Initially, at least, this decision appeared to be a form of external legitimacy work. For example, at a Governance Committee meeting in April 2012, one of the independent directors noted that governance was the 'hot topic' for Sport England and it was important to be seen to be doing something. And at a board meeting that year, one of the elected directors emphasised the legitimising effects of signing up to a code and employing the language of good governance publicly: 'It helps', he said, 'if you speak the same language as your primary funder'.

Over time, however, the board of the federation moved beyond formal adoption towards attempting to use the code to frame their own internal discussions and decision-making. For example, in the November 2012 board meeting, the Chair argued that the Voluntary Code was 'something that we can use to navigate ourselves'. One of the chief executives then ran a board exercise, in which each board member was asked to state which of the seven principles of the Code was most important (in general) and which the federation ought to focus on next. This exercise was followed up in subsequent board meetings. In an interview, one of the independent directors explained how this worked as a semiregular practice:

We take probably one principle now per board meeting, or every other board meeting and we look at it and we discuss it in the wider context of, do we do this, how do we do this, how do we evidence it? Because you have to have that conversation. And how does this inform our strategic thinking going forward?

Our observations indicated that the salience of this kind of internal governance scrutiny, framed by the Voluntary Code, tended to fluctuate over time, and commitment varied among board members. Indeed, one of the elected directors commented in an interview that "We tend to tick off the individual items, [but] some people just sort of zone out during those periods". Nevertheless, it was clear that there were explicit attempts to implement some of the principles of the Voluntary Code and it could not be seen only as external legitimacy work.

Furthermore, over the course of the research, it appeared that formally adopting the Voluntary Code also initiated a kind of internal legitimacy work in the federation, whereby board members developed a narrative for themselves about how well governed they were as an organisation. For example, in the November 2012 board meeting, in discussing Principle 4 of the Voluntary Code, concerning a 'Balanced, Inclusive and Skilled Board', one of the independent directors noted, 'We have a skills matrix, which is a strength'. Others agreed. This internal legitimacy narrative was bolstered by feedback from external bodies. As the Chair said in a subsequent board meeting, "What I heard (...) is that Sport England are appreciative of what we've done. We've done what we said we would do. We are seen as one of the better sports". 
Having said this, there was no question that the prescriptions of the governance codes, when issued by the funding agencies, constrained board autonomy. This was apparent in tangible and intangible ways. For example, there was a long-running plan to make the joint CEOs full members of the board, which was formally agreed at the February 2012 board meeting. This would have increased the board from 12 to 14 members. However, at the same time, Sport England released its governance strategy, On Board for Better Governance, which stated that "Ideally the Board size should not exceed 12 members. In exceptional circumstances where the Board size exceeds this number, the NGB must be able to justify this on the basis of organisational effectiveness" (Sport England 2012, p. 9). Ultimately, through various board discussions and informal discussions with Sport England representatives, it appeared this would not qualify as 'exceptional circumstances' and so the decision to add the CEOs to the board, despite being taken in order to improve organisational effectiveness, was not enacted.

Around the same time, the board was holding a series of discussions to set out the organisation's strategy. Although both the Voluntary Code and Sport England's governance strategy emphasised the importance of organisational autonomy, with the board setting the strategy for the organisation, board members were highly sensitised to the need to align their strategic priorities with those of their main funder, Sport England. As one of the CEOs said in interview:

I mean, there's that sort of dichotomy of, you know, the message from Sport England is that you should first think about what would be good for your sport. And then, you know, they should see what parts of that strategy they would fund. But we don't...in truth, we can't operate like that. We first think about what they're willing to fund.

In this sense, while there was certainly a desire on the part of the board to act autonomously, there was a keen recognition of the importance of aligning their strategy with the broader strategic direction of the main funder (and code issuer).

\section{Discussion: Legitimacy work and its consequences}

Evidence suggests sport federations adopt codes of governance for multiple reasons, including the obvious 'managerial' rationale, i.e. to improve their own governance practices, and the 'necessary for funding' rationale, i.e. when a code is a mandatory set of practices that organisations have to adhere to, in order to receive funding. But in among these, there is another common rationale: adopting a code to demonstrate legitimacy to certain stakeholders, often key (potential) funding bodies and commercial sponsors. This can be seen as external legitimacy work (Lefsrud et al. 2020). But a closer look suggests this can also involve forms 
of internal legitimacy work (Drori \& Honig 2013), whereby action taken is used to build or sustain a narrative for organisation members themselves that, in this case, the organisation is well governed.

As a 'reform strategy', then, adopting a code of governance as legitimacy work can bring benefits to the organisation in terms of credibility in the sector. However, it is not without tensions and contradictions. First, there is the question of whether the focus on demonstrating legitimacy through adopting a code slows down, or de-emphasises, attempts to actually implement the principles themselves. There is, of course, no reason sport federations cannot simultaneously attempt to implement codes of governance, while heralding their adoption to demonstrate legitimacy. However, too much focus on the legitimising aspects may well reinforce a sense among board members that it is formal adoption that counts, rather than seeking to embed principles. This is tied up with the concern among many board members that the codification process, in general, can transform governance into a 'tick-box exercise', crowding out the sense of good governance as a set of embedded cultural values within an organisation.

This tension is exacerbated by the evolution of the codification process in some countries. In the UK, for example, the most recent Code for Sports Governance (Sport England/UK Sport 2016) is mandatory for organisations wishing to receive public funding. This raises a significant question: how far can this really be seen as a code of good governance, rather than, as some respondents called it, the 'terms and conditions of funding'? While the rationale for making it mandatory is clearly stated - to seek to mandate good governance across the sport sectorthere is the concern, as one board member commented, 'that organisations spend their time ticking the box rather than addressing the culture and values of the organisations'.

There is also the significant question bound up with the notion of adopting a code as legitimacy work: legitimacy to whom? As many board members noted, there is a real danger that by seeking to demonstrate credibility to funders and commercial sponsors by appearing more 'business-like' in their governance arrangements, sport federations are alienating many of their (grassroots) members, by de-emphasising the democratic traditions through which people are elected from within the sport to govern the sport. This tension has been highlighted repeatedly in the academic literature on professionalisation in the nonprofit sport sector (Dowling et al. 2014; Kikulis 2000) and it is one key area that highlights the difference between corporate organisations and the kind of member-based, volunteer-reliant sport organisations.

In this sense, the legitimacy work involved in formally adopting a code of governance, which might seem superficial, quickly becomes a much more nuanced, complex process of balancing stakeholder interests and careful discussion, communication and persuasion within particular sports. Over the last few years, Lesley Ferkins, David Shilbury and others have published a series of articles examining precisely these kinds of governance issues (e.g. Ferkins \& Shilbury 2010, 2015; Shilbury \& Ferkins 2015). While these have not put the concept of 'legitimacy 
work' front and centre, they have explored it as part of the broader issues around 'ownership' in the governance of sport federations.

\section{Conclusion}

The first conclusion of this chapter is that codification of governance is here to stay in the non-profit sport sectors of many countries and, where it is not already present, it is gathering pace. While this has been the case in the UK, with our research and empirical analysis based on the level of national sport federations in the UK, the fact that there are now codes in multiple countries means that the empirical findings from this chapter are likely to resonate with the situations and circumstances that other national federations face. Similarly, the growing importance of governance within international federations and accompanying codes (e.g. ASOIF 2016) means that the findings from this research are also likely to resonate with the experiences and pressures faced by international federations. Thus, we argue the research is 'transferable', primarily to national federations in other countries, but also to international federations.

The second conclusion is that, at an organisational level, many boards of sport federations decide to adopt codes of governance, initially at least, as a means of demonstrating credibility to external stakeholders. This is code adoption as legitimacy work. But this is where the plot thickens. Empirical research on codification with board members, especially including observation of board and committee meetings, is relatively rare. But the evidence here suggests that demonstrating credibility to external stakeholders-external legitimacy work-is only one aspect. There are also subtler forms of internal legitimacy work going on, as well as tensions and contradictions raised by the emphasis on adopting codes to demonstrate credibility.

This has implications for researchers and practitioners. For researchers, the first implication is quite simply to recognise that, in the area of governance, legitimacy work is going on. In that sense, analysis of governance codes that conceptualises them only as tools for improvement, or analysis of the adoption of codes that conceptualises it only as a rational action to improve the internal workings of the organisation, will miss important aspects of why and how board members engage with codes. The second implication is to re-emphasise that governance is a multi-level phenomenon (Cornforth 2012). The broader insight from this chapter is that, when it comes to governance, it can be useful to see the various actors, from governments to national sport agencies to individual sport federations, as operating within the same 'regulatory space' (Hancher \& Moran 1989), in which "interest groups are bound together in relations of exchange and interdependence, yet the way in which these parties inhabit the regulatory space is characterised by competition and conflict" (Sharrat et al. 2007, p. 1508). As such, national sport agencies themselves can be involved in legitimacy work, introducing codes (or making them mandatory), in order to position themselves as responsible actors within the regulatory space. The final implication for researchers is 
methodological: as a number of researchers have pointed out, a key means of understanding governance is through 'insider perspectives' of board members and direct observation of governance practices (Leblanc \& Schwartz 2007; Tacon et al. 2017).

As for specific further research, Parent and Hoye (2018, p. 22) conclude their systematic review of research on the impact of governance principles on sport organisations' governance practices and performance by calling for more research on "the capacity and readiness of sport organisations to adopt governance principles and what conditions need to be met for sport organisations to be capable of adopting and implementing these in order to reap some reward in the form of improved governance performance". Along with this, they argue for more research on actual implementation (or non-implementation) of governance principles and, most fundamentally, for clearer definitions of governance performance and further scrutiny of the presumed relationship between adopting and implementing codes and improved performance. We agree with all of this. However, we argue that in pursuing this research agenda, researchers should be sensitised to the legitimacy work going on and incorporate it into their theoretical frameworks, in order to gain a more comprehensive understanding of why and how board members engage with codes and principles.

We also argue that future research on this topic should include a wide range of voices. Our research has looked primarily at the board, privileging board member perceptions. Future research should examine the perceptions of other stakeholders: How do members of particular sports perceive the focus on good governance? How do funders, who influence the strategic direction of sport governing bodies, construct legitimacy and does this align with how board members construct legitimacy? Understanding the perceptions of these two stakeholder groups is particularly important to gain insight into tensions that might exist. For example, the codification of governance is underpinned by a move towards a more 'modern', professionalised organisation and, as such, there is real potential for tension between funding bodies pushing the professionalisation of federations and members for whom the development of the sport-rather than the business-is the highest priority. Given the potential for tension, future research will help to provide more theoretical insight into how boards can address multiple accountabilities (Tacon et al. 2017).

While taking a wider group of stakeholders into account is important for theoretical development, for practitioners, there are similar implications. Many board members of sport federations will already be well aware of the wider political context in which codes of governance are issued and many will have been part of board discussions about the advantages and disadvantages of formally adopting codes of governance. In addition, many will be aware of the tensions involved in seeking to implement governance reforms and may well have divergent opinions on the merits of doing so. However, other board members may not be. As the drive for independent board members continues, many sport federations are deliberately recruiting individuals with little or no background in sport. This 
means newly recruited board members may have little contextual background knowledge about the sector. This chapter, at a basic level, should help to sensitise board members to some of the contests for legitimacy that characterise the codification of governance within non-profit sport. Moreover, it should highlight the ongoing need for board members of sport federations to balance multiple stakeholder interests. While it might seem an 'easy win' to formally adopt a code of good governance and seek to push through the governance reforms being promoted by governments and national sport agencies as part of the modernisation agenda (Tacon \& Walters 2016), this can exacerbate divisions within the existing structures of sports, which can ultimately harm organisational effectiveness. It is a tricky balance to strike, but that is part of the ongoing challenge of governing.

\section{References}

ASOIF 2016, ASOIF Governance Task Force (GTF) - 1st Report to ASOIF Council, ASOIF, Lausanne.

Australian Sports Commission 2005, Governance principles: A good practice guide for sporting organisations, Australian Sports Commission, Canberra.

Aguilera, RV \& Cuervo-Cazurra, A 2004, 'Codes of good governance worldwide: What is the trigger?', Organisation Studies, vol. 25, no. 3, pp. 417-46.

Aguilera, RV \& Cuervo-Cazurra, A 2009, 'Codes of good governance', Corporate Governance: AnInternational Review, vol.17, no.3,pp.376-87.doi:10.1111/j.1467-8683.2009.00737.x

Birkbeck/Moore Stephens 2018, The state of sports governance: Are you leading or lagging?, Moore Stephens, London.

Chappelet, JL 2018, 'Beyond governance: The need to improve the regulation of international sport', Sport in Society, vol. 21, no. 5, pp. 724-34. doi:10.1080/17430437. 2018.1401355

Cornforth, C 2012, 'Nonprofit governance research: Limitations of the focus on boards and suggestions for new directions', Nonprofit and Voluntary Sector Quarterly,vol. 41, no. 6, pp. 1116-35. doi:10.1177/0899764011427959

Dowling, M, Edwards, J \& Washington, M 2014, 'Understanding the concept of professionalisation in sport management research', Sport Management Review, vol. 17, no. 4, pp. 520-29. doi:10.1016/j.smr.2014.02.003

Drori, I \& Honig, B 2013, 'A process model of internal and external legitimacy', Organisation Studies, vol. 34, no. 3, pp. 345-76. doi:10.1177/0170840612467153

Ebrahim, A 2010, 'The many faces of nonprofit accountability', in DO Renz \& RD Herman (eds), The Jossey-Bass handbook of nonprofit leadership and management, 3rd edition, John Wiley and Sons, San Francisco, pp. 101-21. doi:10.1002/9781119176558.ch4

Ferkins, L \& Shilbury, D 2010, 'Developing board strategic capability in sport organisations: The national-regional governing relationship', Sport Management Review, vol. 13, no. 3, pp. 235-54. doi:10.1016/j.smr.2010.01.009

Ferkins, L \& Shilbury, D 2015, 'The stakeholder dilemma in sport governance: Toward the notion of "stakeowner", Journal of Sport Management, vol. 29, no. 1, pp. 93-108. doi:10.1123/jsm.2013-0182

Geeraert, G 2019, 'The limits and opportunities of self-regulation: Achieving international sport federations' compliance with good governance standards', European Sport Management Quarterly, vol. 19, no. 4, pp. 520-38. 
Hancher, L \& Moran, M 1989, 'Organizing regulatory space', in L Hancher \& M Moran (eds), Capitalism, culture and economic regulation, Clarendon Press, Oxford, pp. 271-300. doi:10.1093/acprof:oso/9780198765295.003.0005

Kikulis, LM 2000, 'Continuity and change in governance and decision making in national sport organisations: Institutional explanations', Journal of Sport Management, vol. 14, no. 4, pp. 293-320. doi:10.1123/jsm.14.4.293

Leblanc, RW \& Schwartz, MS 2007, 'The black box of board process: Gaining access to a difficult subject', Corporate Governance: An International Review, vol. 15, no. 5, pp. 843-51. doi:10.1111/j.1467-8683.2007.00617.x

Lefsrud, L, Graves, H \& Phillips, N 2020, “Giant toxic lakes you can see from space”: A theory of multimodal messages and emotion in legitimacy work', Organisation Studies, vol. 41, no. 8, pp. 1055-78. doi:10.1177/0170840619835575

McLeod, J, Shilbury, D \& Zeimers, G 2020), 'An institutional framework for governance convergence in sport: The case of India', Journal of Sport Management, vol. 35, no. 2, pp. 144-57. doi:10.1123/jsm.2020-0035

Meyer, JW \& Rowan, B 1977, 'Institutionalized organisations: Formal structure as myth and ceremony', American Journal of Sociology, vol. 83, no. 2, pp. 340-63. doi:10.1086/226550

Nordberg, D \& McNulty, T 2013, 'Creating better boards through codification: Possibilities and limitations in UK corporate governance 1992-2010', Business History, vol. 55, no. 3, pp. 348-74. doi:10.1080/00076791.2012.712964

Parent, MM \& Hoye, R 2018, 'The impact of governance principles on sport organisations' governance practices and performance: A systematic review', Cogent Social Sciences, vol. 4, no. 1, pp. 1-24. doi:10.1080/23311886.2018.1503578

Pugliese, A, Bezemer, PJ, Zattoni, A, Huse, M, Van den Bosch, F \& Volberda, HW 2009, 'Boards of directors' contribution to strategy: A literature review and research agenda', Corporate Governance: An International Review, vol. 17, no. 3, pp. 292-306. doi:10.1111/j.1467-8683.2009.00740.x

Seidl, D, Sanderson, P \& Roberts, J 2013, 'Applying the 'comply-or-explain' principle: Discursive legitimacy tactics with regard to codes of corporate governance', Journal of Management and Governance, vol. 17, no. 3, pp. 791-826. doi:10.1007/ s10997-011-9209-y

Sharrat, D, Brigham, B \& Brigham, D 2007, 'The utility of social obligations in the UK energy industry', Journal of Management Studies, vol. 44, no. 8, pp. 1503-22. doi:10.1111/j.1467-6486.2007.00736.x

Shilbury, D \& Ferkins, L 2015, 'Exploring the utility of collaborative governance in a national sport organisation', Journal of Sport Management, vol. 29, no. 4, pp. 380-97. doi:10.1123/jsm.2014-0139

Sport and Recreation Alliance 2011, Voluntary code of good governance for the sport and recreation sector, Sport and Recreation Alliance, London. doi:10.1093/ ww/9780199540884.013.u282702

Sport and Recreation Alliance (eds) 2014, Voluntary code of good governance for the sport and recreation sector, 2nd edition, Sport and Recreation Alliance, London. doi:10.1093/ ww/9780199540884.013.u282702

Sport England 2012, Sport England governance strategy: On board for better governance, Sport England, London.

Sport England/UK Sport 2016, A code for sports governance, Sport England and UK Sport, London. 
Suchman, MC 1995, 'Managing legitimacy: Strategic and institutional approaches', Academy of Management Review, vol. 20, no. 3, pp. 571-610. doi:10.5465/amr.1995. 9508080331

Tacon, R \& Walters, G 2016, 'Modernisation and governance in UK national governing bodies of sport: How modernisation influences the way board members perceive and enact their roles', International Journal of Sport Policy and Politics, vol. 8, no. 3, pp. 363-81. doi:10.1080/19406940.2016.1194874

Tacon, R, Walters, G \& Cornforth, C 2017, 'Accountability in nonprofit governance: A process-based study', Nonprofit and Voluntary Sector Quarterly, vol. 46, no. 4, pp. 685-704. doi:10.1177/0899764017691637

UK Sport 2004, Good governance: A guide for national governing bodies of sport, Institute of Chartered Secretaries and Administrators, London.

Walters, G \& Tacon, R 2018, 'The 'codification' of governance in the non-profit sport sector in the UK', European Sport Management Quarterly, vol. 18, no. 4, pp. 482-500. doi: $10.1080 / 16184742.2017 .1418405$ 